\section{A CASE OF SPASMODIC STRICTURE OF THE PYLORUS: PYLOROPLASTY; RECOVERY.}

Br R. SHALDERS MILLER, M.B. LOND, F.R.C.S. ENG.

THE subject of this operation was a single woman aged forty-eight years, of a highly neurotic temperament. About five years ago she developed, somewhat suddenly, intense dyspeptic symptoms, with vomiting of much coffee-ground material, accompanied with great pain and epigastric tenderness. No tumour could be detected. Gastric ulcer or possible malignant disease was suspected, but the symptoms gradually disappeared under medicinal and dietetic treatment. In the spring of 1891 she had a mild attack of epidemic influenza. Except for this she did not require medical attendance until the spring of 1892, when very severe and persistent vomiting set in, but without the appearance of coffee-ground matter. There was again epigastric pain, much increased by food, but no tumour could be felt. There was no elevation of temperature. The case was for a time considered to be due to nervous disturbance, but the patient's general condition became so rapidly worse, with intense pain and emaciation, that cancer was feared, and this opinion was unbesitatingly confirmed by an eminent medical authority. At this time the patient was fed almost entirely by nutrient enemata. Every possible anti-neurotic remedy had been tried without the slightest result, and hypodermic injections of morphia had to be regularly given at night. After these injections food was more easily tolerated by the stomach than at any other time, but such food was found usually to accumulate in the stomach for a diy or two, and was then vomited again with much added fluid. Constipation was extremely obstinate, and purgative enemata produced but little evacuation, the passage of which was attended with great suffering. The emaciation and weakness were so severe that from September, 1892 , till the date of the operation the patient was entirely bedridden. The stomach was for a time considerably dilated, but became less so by the end of 1892 . The menopause was also in progress and catamenia ceased in November, 1892. The patient's condition having been stationary except for slight, gradual, and increasing loss of flesh since the spring of 1893, the operation, so lucidly described by Mr. Pearce Gould, ${ }^{1}$ was recommended and instantly consented to by her. The only special preparations for the operation, which was performed on Aug. 31st, 1893, were the placing of the patient on a hot-water bed and the administration of a dose of quinine so as to render aseptic the contents of the stomach. The steps of the operation were essentially identical with those described by Mr. Pearce Gould, and therefore need no recapitulation, but the conditions found after the abdominal section was made were by no means the same as in his case. The stomach was very little dilated, but the first part of the duodenum was very decidedly so; there were no peritoneal adhesions, and by grasping the gastro-duodenal isthmus obliquely betwe:n the finger and thumb a fair-sized pyloric orifice could be easily made out. For this reason the abdominal wound was enlarged nowards and downwards to allow of a free examination of the organs. The liver, stomach, duodenum, omentum, and transverse colon were found to be perfectly bealthy. The stomach was then opened by an incision in its long axis near the pylorus and the forefinger introduced so as to feel as much as possible of the gastric mucous membrane. Nothing abnormal was discovered. The finger was then passed through the pylorus and was immediately grasped by the spbincter of that aperture. The contraction, however, quickly subsided and the finger was passed down the vertical portion of the duodennm as tar as the orifice of the common bile-duct, which could be readily felt and appeared to be normal. The pyloric sphincter presented a thin, sharp, internal edge, and with the finger inside and the thumb outside the muscular circle was felt to be triangular in section. The incision in the stomach was then continued into the duodenum, and the wound treated as in Mr. Pearce Grould's case. The abdominal wound was closed with numerous silkworm gut sutures and dressed with iodoform powder and alembroth gauze. Ether was skilfully administered by Dr. A. W. Wheatly.

The progress of the patient after the operation as regards symptoms may be briefly summarised as a negation of her previous condition. The highest temperature attained was $99.6^{\circ} \mathrm{F}$. on the day after operation, and thereafter was usually a little subnormal. Feeding by rectum was con tinned, but gradually rednced after the third day, and dis. continued in three weeks. Meat juice and prepared food made with milk were given the day after the operation, and the diet daily increased, meat being given, minced, a week later. There was no vomiting on recovering from the ether, and except for the rejection of a little surplus beef-t $t a$ on the fourth day the patient was never sick again. She was very hungry and took large quantities of food by the mouth, and never complained of pain after her meals. The dressing had to be changed on the third day in consequence of its becoming very damp from perspiration. The wound was found to be well closed, and indeed healed, except here and there the superficial part of the skin had not quite united, a result, no doubt, of its being kept saturated with perspiration. All the parietal stitches were semoved on the twelfth day. The bowels acted on the fourth day with an enema of castor oil and turpentine, the use of which greatly relieved the flatulence. This had been rather troublesome, but not more so than before the operation. Small doses of aloin and belladonna were given three times a day, and in a week the motions were formed, though the rectum had to be excited every second or third day by a small enema of castor oil and turpentine. Assafoetida pills were given, as suggested by Dr. Chepmell in Mr. Pearce Gould's case, and they afforded great relief to flatulent distension and borborygmi, but failed as aperients. The bowels acted naturally on the twenty-third day and continued to do so every alternate day. On the same date (Sept. 23rd) the patient left her bed, after having been absolutely confined to it for just over a year, and returned to her own house from the surgical home exactly a month from the date of operation. Increase in flesh became appreciable about ten days after the operation, but the patient was never weighed, as her previous state would not admit of it.

The present condition of the patient, fifteen months after operation, is eminently satisfactory. She has become quite plump, and is able to take a considerable amount of exercise. Her appetite and digestion are excellent, and except for an occasional attack of migraine she is never sick or in need of medical attendance. There is no tendency to ventral hernia; morphia injections were discontinued a few weeks after the; operation, and a mild aperient pill now and then is all that is needed to keep the bowels in good order.

Remarks. - In this instance the abdominal section was considerably longer than was needed for pyloroplasty, which, as the subjects for it must usually be thin, might be done with an incision of three inches and a half. It seemed needfal to explore the abdomen extensively, as no disease about the pylorus could be found betore making the visceral incision. The case appears to have been of a spasmodic natnre, but the pyloric sphincter was certainly sharper and more prominent internally than normal, and its closure on the finger was notably sudden. Probably the same thing occurred when food approached it. The outer row of sutures in the gastro-duodenal wound were not according to Lembert, but were passed through the peritoneum and muscle about a quarter (or rather less) of an inch from the cut edge, and were brought out on the one side and commenced on the other side of the cut just under the edge of the peritoneal coat. This was done so as not to interrupt the continuity of the longitudinal muscular fibres, which are pretty thick and close together at the pylorus; it was hoped thereby to secure the best possible peristalsis at the critical spot. Possibly the spastic condition found in this instance may explain some cases of actual hypertrophic or fibroid stricturethe constant irritability of the muscle leading to byperplasja as well as hypertrophy, especially if any inflammatory process supervened. In this patient the disease had not lasted long enough to cause more than slight overgrowth of the circular fibres of the pylorus. This is the third pyloroplasty performed in England, so far as I am aware, the first being that of Mr. F. Page and Dr. Limont, ${ }^{2}$ done early in 1892, and the second that of Mr. Pearce Gould in December, 1892 and it is satisfactory to note that all three patients have not only survived the operation but have been completely relieved of their previous disability and suffering.

Windsor. 